\title{
O uso de tecnologias digitais na facilitação da emergência de zonas de desenvolvimento proximal em sala de aula
}

\author{
Juliana Silva Arruda1, José Aires de Castro Filho², Liliane Ramalho de Castro \\ Siqueira $^{3}$ \\ Departamento de Pós-Graduação em Educação Brasileira - CEP 60020-110 - \\ Universidade Federal do Ceará (UFC) - Fortaleza - CE - Brasil. \\ 2 \\ Instituto UFC Virtual - CEP 60440-554 - Universidade Federal do Ceará (UFC) \\ Fortaleza - CE - Brasil \\ Departamento de Contabilidade - CEP 60020-110 - Universidade Federal do Ceará \\ (UFC) - Fortaleza - CE - Brasil \\ julianarruda24@gmail.com, airesevirtual.ufc.br, \\ ramalholilianedyahoo.com.br
}

\begin{abstract}
Brazil is experiencing a period of technological immersion in all areas of society, including in the educational environment. This study aims to analyze how the digital resources used in activities collaboratively, can bring out Proximal Development Zone (ZDP). This research was developed in a municipal school in Aquiraz / CE, in groups of two or more learners, through a qualitative methodology with interpretative character. Involving participant observation with micro genetic analysis. The results highlighted times when resources combined with peer interaction facilitate the emergence of $Z P D$, resulting in learning.
\end{abstract}

Resumo. O Brasil vivencia um período de imersão tecnológica em todas as áreas da sociedade, inclusive no meio educacional. Este trabalho tem como objetivo analisar como os recursos digitais, utilizados em atividades realizadas colaborativamente, podem fazer emergir Zonas de Desenvolvimento Proximal (ZDP). Esta pesquisa foi desenvolvida em uma escola municipal de Aquiraz/CE, em grupos de dois ou mais aprendentes, através de uma metodologia qualitativa, com caráter interpretativo. Envolvendo a observação participante, com análise microgenética. Os resultados destacaram momentos em que os recursos aliados a interação entre pares facilitam a emergência de ZDP, acarretando em aprendizagem.

\section{Introdução}

Silva e Castro [2015] descrevem que as Tecnologias de Informação e Comunicação (TIC) influenciam nos processos de conversação entre as pessoas e se inserem no contexto educacional como resultado de tudo que ocorre ao redor da escola. Sendo assim, a comunicação intermediada pelas tecnologias possibilitam a constituição de novos recursos metodológicos, além de oportunizar o desenvolvimento de atividades com ferramentas facilitando os processos de ensino e aprendizagem. 
Com a disseminação das tecnologias, é possível colaborar tanto na criação de conteúdo, como textos ilustrativos, gráficos, opiniões. Desta forma, percebe-se as TIC estão cada vez mais presentes no dia a dia, desde a busca de informações, comunicação, bem como o uso pedagógico [Castro, 2012].

Esse estudo tem como fundamentação as teorias de Vygotsky [1994] envolvendo a aquisição da aprendizagem e a interpretação Meira \& Lerman [2009] sobre como o uso de ferramentas e as interações propiciam a aprendizagem. Entende-se a aprendizagem a partir do conceito de Zona de Desenvolvimento Proximal(ZDP) da teoria de Vygotsky [1994] que demonstrou a relação dialética entre a distância do Nível de Desenvolvimento Real (NDR), que é o que a criança já consegue realizar e a Nível de Desenvolvimento Proximal (NDP), que é tudo que a criança não consegue realizar sozinha, mas tem o potencial, pois com a ajuda de alguém mais experiente consegue fazer. Sendo assim, mesmo que a criança ainda não esteja desenvolvida para realizar determinada tarefa, ela pode fazer com ajuda de alguém mais experiente, e assim, aprende e também se desenvolve [DAVID, 2012].

$\mathrm{Na}$ presente pesquisa, considera-se a visão de Meira e Lerman [2009], caracterizando a ZDP como um espaço semiótico construído durante atividades nas quais os pares, professores ou outros recursos propiciam uma aprendizagem. Dessa forma, ela não é pré-existente, não é algo concreto ou uma caixa fechada, e sim um espaço simbólico de interação e comunicação onde a aprendizagem acarreta no desenvolvimento. A pesquisa originou-se da seguinte questão: As atividades interativas, utilizando o computador como um recurso, potencializam a aprendizagem dos aprendentes?

O trabalho tem como objetivo analisar de que maneira o desenvolvimento do aprendente pode ser potencializado, utilizando o conceito de ZDP, considerando o netbook como uma ferramenta que pode propiciar maneiras de desenvolvimento quando utilizados em atividades realizadas de forma interativa, dentre os recursos utilizados temse o facebook e atividades interativas entre os alunos intermediadas por estes instrumentos de mediação entre os alunos. Sendo assim, os diálogos mediados por esses recursos e ferramentas online puderam favorecer a constituição de procedimentos metodológicos, oportunizando novas vivencias e auxiliando no processo de ensino e aprendizagem [SILVA E CASTRO,2015].

Justifica-se o estudo considerando que as tecnologias a cada dia se apresentam como uma realidade das escolas brasileiras, no entanto, muitas vezes se desconhece o seu verdadeiro potencial. Busca-se esclarecer o uso pedagógico das TIC em sala de aula O texto está estruturado da seguinte forma: a próxima seção discute a definição da ZDP sob a luz de diferentes olhares e a integração das tecnologias na educação, seguida dos procedimentos metodológicos, finalizando com os resultados, as considerações finais e as referências.

\subsection{A conceituação da Zona de Desenvolvimento Proximal(ZDP)}

Em sua primeira formulação, Vygotsky [1994], demonstrou o conceito de ZDP, através da relação dialética entre o Nível de desenvolvimento real (NDR) e o Nível de Desenvolvimento Proximal (NDP). Sendo ZDP a distância entre o NDR, que representa o que o sujeito já consegue realizar e o NDP, que é tudo que ele não consegue realizar sozinho, mas tem o potencial, pois com a ajuda de alguém mais experiente terá possibilidade de fazer. Sendo assim, mesmo que ele ainda não esteja desenvolvido para realizar determinada tarefa, ele pode fazer com ajuda de pares, e assim, aprende e também se desenvolve. 
Autores como David [2012] consideram essa primeira conceituação como limitada, visto que somente o desenvolvimento particular das funções psicológicas são demonstradas. Sendo a ZDP vista como meio físico delimitado, espaço este que deveria ser alcançado pelo professor, só assim a aprendizagem aconteceria.

Neste estudo, a ZDP é considerada de maneira ampliada, assim como Meira e Lerman [2009] a consideravam como um espaço construído durante atividades nas quais colegas, professores ou outros recursos propiciam uma aprendizagem. Dessa forma, ela não é pré-existente, não é algo concreto ou uma caixa fechada, e sim um movimento dinâmico de interação e comunicação em que a aprendizagem acarreta no desenvolvimento.

Na sala de aula, a ZDP se desenvolve a partir da postura do professor e das atividades por ele intermediadas, e também pelas maneiras do estudantes, comunicar-se e agir [MEIRA, LERMAN, 2009]. Dessa maneira, para esses autores, o primeiro objetivo da ZDP se caracteriza como um espaço simbólico de ensino e aprendizagem, estabelecido por pessoas em interação em uma atividade, se desenvolvendo por um processo de contínua transformação. Considerando três diferentes formulações para ZDP: performance; interação e mediação semiótica. Na primeira, a ZDP seria um espaço do aluno onde o professor teria que encontrar e saber qual circunstância que a ZDP ocorre e tentar acessá-la. Com relação à interação, ela é uma continuação da primeira, mas considera os meios sociais e a orientação em substituição à análise de performance. A mediação semiótica considera a ZDP como como um meio semiótico, um processo dinâmico que se desenvolve entre sujeitos em atividade.

Pesquisas como de Luckin et al [2005] analisam as contribuições das ferramentas interativas para aprendizagem, demonstrando a utilização de softwares educativos facilitadores da compreensão das representações de um conceito. Discutindo ainda a importância da aprendizagem com um foco particular sobre a aplicação educativa das tecnologias móveis.

Estudos analisaram as estratégias usadas pelos professores da educação básica utilizando a tecnologia através de objetos de aprendizagem. Como resultados concluíram que a função do professor é organizar, através de uma metodologia criteriosa, atividades que facilitem a aprendizagem do aluno e a relação com o computador.

\subsection{Integração das Tecnologias nas Educação}

Para Webber e Vieira [2010], a inserção do computador em atividades educativas remete ao uso de linguagens e aprendizagem de conceitos, trazendo contribuições para a sala de aula. Os estudos dos pesquisadores analisaram o uso de recursos digitais na facilitação de projetos educacionais, trazendo benefícios para escola. Embora não apontem suas pesquisas especificamente para ZDP, o estudo traz contribuições para esse estudo.

Considera-se que apesar da aprendizagem móvel ocorrer em ambientes sociais diversos e em projetos pedagógicos diferentes, os dispositivos vem contribuindo para o processo de aprendizagem. Visto que estes fornecem aos alunos variadas vivências de aprendizagem em diferentes contextos, proporcionando uma rede de conhecimento que independe da localização temporal e espacial, podendo ser na residência, escola e em qualquer outro contexto [LIMA, LIMA NETO, CASTRO, 2015].

Considerando as instituições educacionais em um contexto onde ocorre a inserção de computadores em atividades do currículos, os recursos digitais podem ser utilizados 
como um meio que proporciona a interação, tanto em atividades em pares como individuais, relacionado ideias e argumentações ou analisando diferentes contextos.

Estudos recentes como Nascimento [2012] e Luckin, et al [2005], Colaço [2004] buscam compreender como o desenvolvimento e a aprendizagem ocorrem e quais fatores podem facilita-los, considerando a tecnologia e seus recursos como meios de potencializar a emergência desses processos.

As pesquisas de Nascimento [2012] analisam a facilitação da aprendizagem a partir do uso de recursos, que fornecem mecanismos para atividades colaborativas na educação, tendo como contexto uma sala de aula do Projeto Um Computador por aluno-UCA. Chegando a conclusão que o uso do recurso digital pode promover a comunicação e a colaboração, possibilitando transformações na práxis educacionais.

Os autores Luckin, et al [2005] concluíram que a utilização adequada dos recursos tecnológicos maximiza a quantidade de assistência que o aluno pode absorver de seu ambiente, assegurando seu direcionado para emergência de ZDP. Pesquisaram a aprendizagem no contexto sócio-cultural de Vygotsky, considerando o conceito de ZDP como uma metáfora que configura a capacidade potencial do sujeito, utilizando a relação entre a diferença no que ele já consegue realizar sozinho e o que ele consegue fazer com assistência. Sendo um processo dinâmico e construído através das interações sociais entre o aluno e os outros(alunos e professores).

Em um de seus trabalhos, Colaço [2004] desenvolve um estudo teórico sobre as interações das crianças, estas sendo consideradas como mediadoras na construção do conhecimento compartilhado e da subjetividade. Utilizando a teoria de Vygotsky e teoria da linguagem de Bakthin. O estudo envolve três categorias: mediação semiótica, ZDP e subjetividade. Conhecimento e subjetividade nascem do contexto social, a interação sendo toda a base do processo de desenvolvimento.

Ainda sobre os estudos da referida pesquisadora, o intercâmbio entre a construção de conhecimento e subjetividade é um espaço semiótico onde pode surgir a ZDP, abordando o conceito de ZDP, partindo da visão de Vygotsky [1994] e Meira e Lerman [2009] a partir da análise do diálogos do alunos na realização de atividades. No entanto, eles não utilizam a tecnologia como recurso, e sim as atividades desenvolvidas pelos professores, abordando também a construção da subjetividade dos alunos. No caso, dessa pesquisa será focada a emergência de ZDP, e não se considerará a subjetividade.

\section{Contexto e procedimentos metodológicos}

\subsection{O Projeto EDigital}

Essa pesquisa foi desenvolvida dentro do contexto do projeto EDigital, em uma escola municipal de Aquiraz (CE), com o apoio da UFC Virtual e a Secretaria Municipal de Educação e a Companhia Energética do Ceará- Coelce. O objetivo principal do projeto é desenvolver competências através do programa de formação voltado ao uso pedagógico de computadores, organizado em ações para implantação do projeto de tecnologia educacional. Dentre as ações contempladas pelo referido projeto, está o desenvolvimento de projetos colaborativos com o uso das TIC, tais como formação de professores e formação de alunos monitores .

Para o desenvolvimento do trabalho, foram 28 participantes do grupo de alunos monitores. O critério de escolha dos participantes foi pelo grupo de alunos monitores do $6^{\circ}$ ao $9^{\circ}$ ano da escola, por estarem processo de formação e com maior acesso e facilidade 
na utilização dos recursos digitais no cotidiano pedagógico.

\subsection{Caracterização do tipo e do método da pesquisa}

A metodologia tem abordagem de natureza qualitativa, considerando que as observações e as estratégias utilizadas pelos sujeitos serão analisadas e interpretadas. Bogdan e Biklen [1994] definem o estudo qualitativo como rigoroso e sistêmico.

Esses autores consideram ainda que, por meio do estudo qualitativo, as informações coletadas têm como característica detalhes sutis e específicos, e que, por essa razão, proporcionam melhor compreensão dos processos educacionais e psicológicos da aprendizagem.

Meira [1994] considera que a análise qualitativa de processos cognitivos se torna complexa, pois envolvem aspectos emocionais, mudanças sensíveis e breves de gestos e comunicações. Existindo duas formas de análises que podem ser utilizadas para instrumentalizar a coleta e análise dos dados nas investigações de processos cognitivos e emocionais: a microgenética, que envolve um rebuscamento minucioso das trocas entre os sujeitos e o contexto e a videografia, que é a filmagem das situações.

No presente estudo, a linha teórica sociocultural, aliada aos aspectos culturais, bem como ao sujeito em atividade ao longo de seu desenvolvimento, soma-se à análise microgenética. Os instrumentos e as técnicas de apreensão de dados contemplaram a observação, o caderno de registro, vídeos, áudios, fotos e entrevista durante o as atividades com o uso das TIC. A análise microgenética caracterizou-se por fornecer minúcias do processo relacional e a interpretação de maneira detalhada.

\subsection{Análise dos dados}

Para ser realizada a análise de dados, os vídeos e áudios foram organizados por dia e turno, separando as turmas. Em seguida, todos foram transcritos e avaliados, considerando aspectos como interações e discussões e de situações, que demonstraram relação com estudo. Posteriormente, foram selecionadas e detalhadas de acordo com suas características e semelhanças formando três categorias.

Em seguida, foram selecionados exemplos e situações; além de registros fotográficos e fragmentos de vídeos, recortes dos trabalhos desenvolvidos com os netbooks $e$ da ferramenta facebook que embasassem cada categoria. Foram divididos por tipo de dado, sempre surgindo novos acontecimentos que demonstravam relação e justificavam o objetivo do estudo.

Em outro momento a partir da leitura inicial dos dados confrontadas com o referencial teórico, foram propostas três categorias: 1) Interação entre pares; 2)Interação com mais experiente e 3) Suporte da Tecnologia.

A primeira categoria, interação entre pares, é compreendida a partir do diálogo de dois ou mais alunos, onde um espaço dinâmico para conversação foi estabelecido, e os aprendentes tiveram a oportunidade de discutir questões. Considera-se também conhecimentos em que o aluno ainda não tinha compreensão e que a partir da conversa com o colega juntos negociam um novo conceito comum a todos.

$\mathrm{Na}$ categoria interação com mais experiente foram considerados os diálogos dos alunos com alguém mais experiente, no caso a pesquisadora. Esta desempenhava uma função de constituir espaço de interação dos alunos com os conhecimentos, com os pares e com ela mesma, promovendo reflexões e intervenções a partir do próprio discurso dos aprendentes. 
$\mathrm{Na}$ terceira categoria, suporte da tecnologia, foi detalhado o envolvimento dos alunos com as atividades em rede, e todas as características desse diálogo mediado por esse recurso. Foram listadas as contribuições da rede para emergência de ZDP dos alunos.

As ZDP e vários outros conceitos como mediação, interação puderam ser verificados a partir da emergência de novos conhecimentos, formação de significados ligados aos temas estudados. Outros fatores que evidenciam a emergência de ZDP foram a demonstração da construção de novas habilidades e dos espaços dinâmicos constituídos a partir da conversação e do diálogos entre os alunos, professores e pares.

\section{Resultados}

Os resultados desse estudo são demonstrados tendo como base as categorias que foram acordadas na análise de dados, partindo dos aportes teóricos sobre a ZDP. Outros conceitos da teoria sócio interacionista, tais como mediação, interação, protagonismo, ativismo estudantil e autonomia também marcaram esses resultados. Importante considerar que essas categorias não se encontram isoladas, há uma relação entre elas, apesar de terem alguns aspectos semelhantes nos seus conceitos.

\subsection{Interação entre pares}

Conceitua-se como interação entre pares quando se estabelecem nas entrelinhas conversações e diálogos estabelecidos entre os alunos, demonstrando a ZDP como um espaço dinâmico que se constitui a partir dessa interação. Além disso, considera-se quando dois alunos ou mais conversam entre si sobre um tema e que antes não tinham entendimento e a partir do diálogo, negociam uma definição para esse conceito até então desconhecido.

Nos próximo exemplo, serão demonstrados diálogos dos participantes, envolvendo a negociação entre pares através da discussão de conceitos que surgiram a partir dos trabalhos realizados com os alunos. que demonstra a interação entre pares foi no momento em que foi postado no facebook um link de uma reportagem. Esta defendia a cobrança de multa para as pessoas que colocassem lixo na rua, sendo proposto para o grupo uma discussão sobre o assunto. Então, feita uma enquete a maioria dos alunos concordava que a multa deveria ser cobrada, pois só assim "as pessoas iriam aprender, doendo no bolso". Vejamos:

\section{Exemplo 1. Discussão sobre a cobrança de multa para quem coloca lixo na rua.}

Aluna A: Tem que ser é preso mesmo. Moleza demais jogar lixo no chão. Vamos botar lei aqui!!!!

Aluna J: Tem que pagar multa mesmo, negocio de jogar lixo no chão aqui, tem isso não Aluna I: As vezes, as pessoas não tem a consciência, a educação de casa, não mexe com o bolso aí resolve, a ignorância das pessoas. Não concordo em cobrar dinheiro, multa.

Aluno $C$ : achava que era certo cobrar o dinheiro, porque ai o governo ia investir nas estradas, na saúde e na educação.

Aluna I: Mas, Aluno C, a prefeitura e o governo não investem o dinheiro nas ruas, na saúde e educação, e eles ficam com o dinheiro.

Aluno C: É mesmo né? O dinheiro nunca fica pra gente, sempre fica pros políticos. Vou mudar de opinião, eu não tinha visto por esse lado.

Aluna I Como sugestão, eles poderiam colocar uma atividade comunitária ao invés de pagar $R \$ 100,00$, como uma punição, porque o governo não investir em coisas para o povo. 
V Congresso Brasileiro de Informática na Educação (CBIE 2016)

Anais dos Workshops do V Congresso Brasileiro de Informática na Educação (CBIE 2016)

Aluna A: É mesmo Aluna I, eles tão só cobrando a multa, a prefeitura também tem que se educar. Tao só cobrando o dinheiro, não tem o projeto.

Aluna J: Tá aí que eu não tinha pensado nisso! Sendo assim, não adianta de nada cobrar essa multa... Bom mesmo era se tivesse educação pra esse povo!

No exemplo 1, todos os alunos incialmente estavam relendo a reportagem a partir da punição financeira como saída para o problema. A partir da releitura da Aluna I que mostrou outro lado e as consequências, constituindo um espaço de diálogo e conversação fazendo com que ZDP emergissem, acarretando a aprendizagem dos Alunos J, C e A que conseguiram agora formar novos conceitos, e ampliar seus conhecimentos.

Através da análise desse exemplo fica evidenciado uma mudança de posição sem necessariamente indicar se antes o aluno não sabia ou estava errado, demonstrando a constituição de espaço dinâmico de conversação, comunicação e de interação entre os alunos.

No momento em que a Aluna I consegue expor suas concepções através do diálogo, compartilhando ideias com os pares, e através dessa troca conseguem constituir novas ideias e interpretações, se evidencia a função social da interação, que proporciona a comunicação entre pares. Relacionando a David [2012], que tem como base os estudos da teoria vygostkyana, definindo a aprendizagem bem sucedida como um adiantamento ao desenvolvimento. Sendo assim, o aprendizado promove a formação dos processos internos de crescimento, e estes têm seu início a partir das atitudes dos sujeitos quando estão interagindo entre si.

\subsection{Interação com alguém mais experiente}

Caracteriza-se como a discussão com alguém mais experiente quando é estabelecido um diálogo com um aluno ou mais, e a partir dessa conversação, o participante que ainda não conseguia entender um conceito passa a compreendê-lo. Outro aspecto importante da ZDP é que ela também se relaciona com o desenvolvimento de uma compreensão conjunta sobre algo, ou seja, duas ou mais pessoas que podiam ter concepções diferentes, começam através de uma conversa a ter uma compreensão comum e também pode-se notar mudanças conceituais, a partir da interação.

O exemplo 2 demonstra o questionamento logo após a apresentação de um vídeo e da aula expositiva, percebe-se que com essas suas atividades, os alunos ainda se apresentavam confusos. Após essa metodologia, a pesquisadora faz um questionamento sobre o que é lixiviação que é um dos temas que foi discutido nas tarefas anteriores, e os alunos não conseguiram responder, demonstrando que o vídeo e aula não foram suficientes. Quando foi perguntado aos três membros de um grupo o que era lixiviação, a aluna D demonstra que entendeu, enquanto os Alunos A e M não conseguiram entender, a partir da interação com a Aluna D e a pesquisadora, os aprendentes constituíram seu próprio conceito.

\section{Exemplo 2. Conceito de Lixiviação}

Pesquisadora: $O$ que seria lixiviação?

Aluna D: é um processo de extração de uma substancia presente em componentes sólidos. É diferente de percolado.

Pesquisadora: Alguém entendeu o que a Aluna D falou.

Aluna A: Entendi.

Pesquisadora: Então, explica para os amigos.

Aluna A: Não sei , na verdade não entendi.

Aluno M: Entendi que é o lixo que se dissolve. 
V Congresso Brasileiro de Informática na Educação (CBIE 2016)

Anais dos Workshops do V Congresso Brasileiro de Informática na Educação (CBIE 2016)

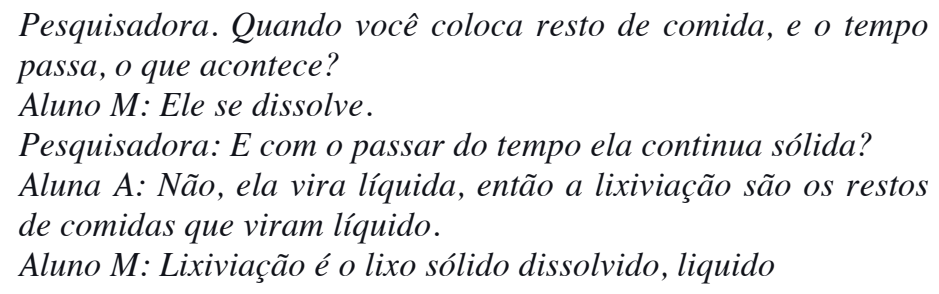

Com esse exemplo, percebe-se que inicialmente a pergunta da pesquisadora proporcionou que aluna $\mathrm{D}$ e $\mathrm{M}$ demonstrassem o entendimento do conceito a partir da visualização do vídeo e das aulas. Mas, no entanto a aluna A apesar de afirmar que havia entendido, quando foi solicitada para explicar para os colegas, ela relata que realmente não compreendeu. A partir do momento que a pesquisadora torna o conteúdo próximo da realidade dessa aluna, através das seguinte questões: "Quando você coloca resto de comida, e o tempo passa, o que acontece?; E com o passar do tempo ela continua sólida?; a aprendente torna-se participante dessa interação, e demonstra no final sua compreensão do conceito, sendo complementada pelo aluno $\mathrm{M}$.

\title{
4.3. Suporte da Tecnologia
}

As atividades que envolveram tecnologia foram planejadas de forma a serem desafiadoras e sensíveis à assistência da pesquisadora e dos pares, envolvendo os conhecimentos e os assuntos estudados pelos alunos.

Essa categoria envolve o desenvolvimento de espaços semióticos de aprendizagem com o uso das tecnologias digitais como recurso. Sendo as situações de aprendizagem determinadas pelo contexto adequado, a tecnologia pode propiciar um ambiente desafiador e fomentador de ZDP.

Neste trabalho foram desenvolvidas atividades com o uso da tecnologia com o objetivo de ajudar os alunos a compreender um determinado conjunto de conceitos ou habilidades relacionados ao conteúdo estudado que é sustentabilidade. O exemplo 3 , é uma transcrição de uma interação que ocorreu através da rede social facebook. Primeiramente, foi postado um texto sobre a conceituação dos 3RS na página da rede social, e os alunos comentaram, acabando por construir um texto como produto final, todo feito em grupo e com informações que iam se complementando.

\section{Exemplo 3 . Construindo o conceito de 3 RS}

\author{
Aluno N: Reutilizar e o uso de um produto mais \\ de uma vez independente da mesma função ou não. \\ Aluno M: Reciclar é ato de usar objetos como pet, latas \\ Aluna A: podendo transformar em novos objetos \\ Aluna L: reduzir e reduzir o consumo de coisas \\ necessárias no nosso dia a dia \\ Aluna A: e acumular menos lixo
}

No Exemplo 3, inicialmente foi apresentado aos aprendentes um vídeo ${ }^{8}$ que abordou o tema 3RS, logo após a exibição foi perguntado aos alunos a definição de 3RS oralmente, proporcionando vivências de diálogo e de troca de ideias. Depois de realizada essa discussão, foi questionado novamente agora pelo facebook a definição e eles conseguiram ir além do que foi proposto, posto que incialmente foi solicitado, 
consituiram um texto coletivo e conectivo, em que um complementou o pensamento do outro, corroborando para a turma ir além do que foi proposto incialmente.

Observa-se que o aluno $\mathrm{N}$ introduziu um conceito sobre reutilizar, $\mathrm{M}$ completou seguido da a aluna A e L, e aluna A finalizou o conceito. Os aprendentes conseguiram construir um texto de uma forma colaborativa, indo além de apenas expor seu pensamento isolado e individual sobre o conceito de $3 \mathrm{Rs}$, eles complementaram e fizeram uma produção com começo, meio e fim de maneira coletiva e socializada.

Demonstra-se, portanto, o desenvolvimento de ZDP através da apresentação de um conceito de 3Rs até então desconhecido, visto que foram questionados antes da visualização do vídeo. Passando a conhecer depois deste último que mostrava situações do cotidiano escolar envolvendo o tema e através das discussões em grupo. A partir da construção de um colega conseguiram dar continuidade e constituir um texto lógico e contextualizado.

No decorrer desse capítulo, foi demonstrada a análise dos resultados, retratando vivências que evidenciaram interações e conversações entre os aprendentes mediadas pela utilização dos recursos digitais. Esse processo aliado ao compartilhamento de conhecimentos facilitaram as emergências de ZDP.

\section{Considerações Finais e Estudos Futuros}

As atividades realizadas e o projeto de uma maneira geral proporcionaram aos educandos a oportunidade de criar textos, produzir histórias, gráficos a partir do uso dos recursos digitais.

Os resultados encontrados relacionados as categorias analisadas, revelam os vários meios e oportunidades provocadas pelo computador, fornecendo diferentes maneiras dos educandos explorarem os conteúdos propostos. Somando-se a este parâmetro, outros critérios encontrados, não menos importantes, tais como o protagonismo, a participação, a mudança de conceito sinalizam a importância da utilização do computador na potencialização da aprendizagem.

Considera-se também que os alunos se sentiram construtores do próprio conhecimento com a produção de vídeos e outros materiais, bem como a divulgação do projeto pelas redes.

Corroborando com resultado desse estudo, traz-se os trabalhos de Luckin et al [2005] e David [2012] que em suas pesquisas trazem discussões sobre a relação entre a aprendizagem e a interação entre pares, e concluem que a intervenção do professor e o auxílio conjunto entre os alunos, os levam a uma melhor compreensão dos conceitos intermediados pela aplicação das tecnologias. Destaca-se que esses trabalhos ainda não relacionam ao surgimento da ZDP, mas utilizam a teoria sócio-histórica como base teórica de suas pesquisas.Com os resultados encontrados nesse estudo, considera-se que o uso de ferramentas e as interações propiciam a emergência de ZDP, assim como Meira e Lerman [2009] teorizam.

Por fim, ressaltando a proposição do objetivo principal dessa pesquisa e considerando os conhecimentos dos autores anteriormente citados, os resultados deste estudo comprovaram que as atividades em pares e a interação intermediadas pelo uso do computador, proporcionam situações de aprendizagem. 
Como estudos futuros, uma pesquisa mais especifica sobre a interação e suas interfaces com a aprendizagem do educando e o desenvolvimento de outras temas geradores que dessem a oportunidade de avaliar diferentes recursos digitais e dispositivos moveis e sua aplicabilidade.

\section{Referências}

BOGDAN, R.C; BIKLEN, S.K.(1994) "Investigação qualitativa em educação". Porto, Portugal: Porto Editora, 1994.

CASTRO, J. B. (2012).’Projeto Um Mundo de Informações: Integração de Tecnologias Digitais ao Currículo Escolar". I CBIE. Workshop sobre formação e experiências educacionais no programa Um Computador por Aluno. Rio de Janeiro.

COLAÇO, V(2004)."Processos interacionais e a construção de conhecimento e subjetividade de crianças”. Psicologia Reflexiva Crit. vol.17 no.3 Porto Alegre.

DAVID, P. B.(2012). "Sistema de Análise de Interações Contingentes: Uma Contribuição para Práticas Interativas em Cursos a Distância”. Revista e-Curriculum (PUCSP), v. 8, p. 1-28.

LIMA, S. M. ; LIMA NETO,C; CASTRO FILHO, J. A (2015). “Aprendizqagem móvel no Ensino Fundamental".Workshop do IV Congresso Brasileiro de Informática na Educação. Maceió.

LUCKIN, R., du Boulay, B., Smith, H., Underwood, J., Fitzpatrick, G., Holmberg, J., Kerawalla, L., Tunley, H., Brewster, D. \& Pearce, D. (2005). "Using Mobile Technology to Create Flexible Learning Contexts.Journal of Interactive Media in Education".

MEIRA, L. (1994). Análise microgenética e videografia: ferramentas de pesquisa em psicologia cognitiva. Revista Temas em Psicologia , n.o 3: Universidade Federal de Pernambuco.

MEIRA, L. ; LERMAN, S. (2009)“Zones of Proximal Development as fields for communication and dialogue". In: Challenges and strategies for studying human development in cultural contexts. Roma: Firera Publishing. p. 199-220.

NASCIMENTO, Karla A. S. Do(2012). "Desafios para Utilização de Atividades Colaborativas em Sala de Aula: um exemplo com o Google Maps". Jornada de Atualização em Informática na educação , v. 1, p. 121-141.

SILVA, M. A. ; CASTRO FILHO, J. A (2015). "Trabalho Colaborativo com Suporte do Laptop: parceria entre professores e alunos". Workshop do IV Congresso Brasileiro de Informática na Educação. Maceió.

VYGOTSKY , L.S. (1994) “A Formação Social da Mente”.São Paulo: Martins Fontes.

WEBBER,C. G.;VIEIRA,M. B. (2010).“Tecnologias Digitais na Educação: colaboração e criatividade em sala de aula". Disponível em: http://revistapos edu.br/index.php/rencima/article/viewFile/16/8.Acesso em 26 abr de 2016. 